\title{
9. DOWNHOLE MAGNETIC MEASUREMENTS IN OCEANIC CRUSTAL HOLE 395A ON THE MID-ATLANTIC RIDGE ${ }^{1}$
}

\author{
V. N. Ponomarev and V. L. Nechoroshkov, Institute of Geophysics ${ }^{2}$
}

\begin{abstract}
Magnetic measurements of the vertical field component and of magnetic susceptibility were made within the ocean crust in Deep Sea Drilling Project Hole 395A on the Mid-Atlantic Ridge during Leg 78B. The variations in the vertical anomalous component of the field confirm the reversals of magnetization in the section described by Johnson (1979a). The reversals are shown to be very sharp, and are concluded to represent breaks in volcanism within which field reversals occurred. The continuous log of the vertical component of the field gives a far more complete and detailed view of the magnetic stratigraphy than was obtained from the minicores alone.

The susceptibility log shows two positive anomalies in the upper part of the section that probably relate to the presence of serpentinite in the walls of the hole. At one of these horizons some serpentinite was recovered in the core but not at the other. The log thus provided a valuable and sensitive adjunct to the recovered samples.
\end{abstract}

\section{INTRODUCTION}

The first downhole magnetic measurements within the ocean crust were made in Holes 501, 504B, and 505B on Legs 68 and 69 of the Deep Sea Drilling Project. The results of those experiments were reported by Ponomarev and Nechoroshkov (1983). The same instrument (the Soviet-built KCM-65 CI [CWM-65]) was deployed in the ocean crust for a second time on Leg 78B of the Deep Sea Drilling Project when Hole 395A (originally drilled on Leg 45 ) was reentered in order to conduct logging and downhole experiments.

The instrument was described in our previous paper (Ponomarev and Nechoroshkov, 1983). Briefly, it is a continuously operating three-component fluxgate magnetometer and susceptibility meter combined. The three elements are oriented by gimbals to give the vertical component of the field and two horizontal components, one parallel to the direction of the dip of the drill hole and the other two at right angles to it. The vertical component can be read in holes deviating from the vertical by up to $20^{\circ}$. To avoid instability in the horizontal orientation, the hole must deviate from the vertical by more than $2^{\circ}$. Unfortunately, Hole $395 A$ was within $1^{\circ}$ of the vertical, so the horizontal components were not stable and could not be used in interpretation. Essentially continuous magnetic field date are recorded. The bed resolution for susceptibility is 10 to $20 \mathrm{~cm}$, again, essentially continuous for DSDP boreholes. As for other downhole logs, ship's heave generates vertical oscillations of the instrument, which affect the details of the record.

The interpretation of the record is based on theory that is outlined in Ponomarev and Nechoroshkov (1983) and in greater detail in Ponomarev and Bakvalov (1969). An important parameter is $Q_{z}$, equivalent in some ways to the Konigsberger ratio of rock magnetism.

\footnotetext{
${ }^{1}$ Hyndman, R. D., Salisbury, M. H., et al., Init. Repts. DSDP, 78B: Washington (U.S. Govt, Printing Office).

2 Address: Institute of Geophysics, Pervomayskaya 91, Sverdlovsk 620169 USSR.
}

$\mathrm{Q}_{\mathrm{z}}$ is defined by:

$$
\mathrm{Q}_{\mathrm{z}}=\left(\mathrm{Z}_{\mathrm{a}}-\mathrm{Z}_{\mathrm{n}}\right) / \mathrm{Z}_{\mathrm{n}}
$$

where $\mathrm{Z}_{\mathrm{a}}$ is the vertical anomalous field (measured inhole vertical component minus regional vertical component), and $Z_{n}$ is the induced vertical field given by:

$$
\mathrm{Z}_{\mathrm{n}}=[(\mathrm{N} \cdot \mathrm{k}) /(4 \pi+\mathrm{N} \cdot \mathrm{k})] \mathrm{Z}_{\mathrm{o}}
$$

where $Z_{0}$ is the regional vertical component of the Earth's field, $\mathrm{k}$ the susceptibility, and $\mathrm{N}$ a geometrical factor. Because we can assume that the horizontal dimensions of magnetic units are much larger than their vertical dimension, $N$ may be taken to be $4 \pi$. For $Q_{z}$ $\gg 1$, a dominance of remanent over induced magnetization is indicated (see Fig. 1, $\mathrm{A}_{2}-\mathrm{A}_{4}$ ).

Although the record from Hole $395 \mathrm{~A}$ is not a complete one because of the absence of horizontal components of the in-hole field, it is still a very valuable addition to the preexisting minicore data (Johnson, 1979a). The magnetization of minicores may be measured with great accuracy, but this record provides only a discrete and discontinuous sample of hole magnetization. In DSDP crustal holes, 2 to 5 samples are typically taken for magnetic measurements from each 9-m core interval. In addition, core recovery is generally poor-less than $20 \%$ in Hole 395A. The low recovery introduces a sampling bias, because only the more massive units are easily recovered, and makes the sampling depth within the $9 \mathrm{~m}$ poorly known.

When the horizontal components of the field are available these allow the calculation of the virtual geomagnetic pole for each interval of the hole, an important addition to the information from minicores, from which only inclination and not declination can be obtained. Such information could not, however, be calculated for Hole 395A.

In the interpretation of downhole magnetic field measurements it is important to remember that the 
fields measured reflect the magnetization of rock volumes at considerable distances as well as those constituting the hole walls, though against the background of long wavelength anomalies caused by distant rocks there are usually sharp, short wavelength anomalies related to the lithology of the hole walls.

\section{RESULTS}

Hole 395A, situated in the Atlantic Ocean at $22^{\circ} 45.35^{\prime} \mathrm{N}, 46^{\circ} 04.90^{\prime} \mathrm{W}$ was drilled on Leg 45 to a depth of $571 \mathrm{~m}$ into the basement (Melson, Rabinowitz, et al., 1979). It lies within Magnetic Anomaly 4 on crust of an estimated age of 7.2 Ma. For various complex reasons no downhole measurements were made at the time of drilling, but the opportunity arose to remedy this deficiency on Leg 78B.

The vertical components of magnetic field intensity and magnetic susceptibility were measured in Hole 395A over the interval from 4597 to $5091 \mathrm{~m}$ below sealevel. This is equivalent to the interval between 19 and $513 \mathrm{~m}$ into the basement. The upper limit corresponded to the lower end of the casing, and the lower limit to the greatest depth to which the instrument could be safely lowered into the hole.

Figure 1 shows a log of both of the measured variables plotted against depth in the hole. The vertical component of the field has been converted to the vertical anomalous component by subtraction of the vertical component of the regional field $(-26000 \mathrm{nT})$. Also on Figure 1 is shown a simplified lithologic column adapted from Natland (1979) and projections of core sample magnetization vectors from Johnson (1979a). Magnetic susceptibility varies in general slowly down the hole between values of 1.0 and $1.3 \times 4 \pi \times 10^{-3}$ SI units. This range is somewhat lower than the average of 2.1 from sample measurements (Johnson, 1979b).

The susceptibility deviates from this in two parts of the hole. Between 79 and $114 \mathrm{~m}$ sub-basement there are two irregular peaks in which short wavelength spikes reach values of 1.7 to $2.1 \times 4 \pi \times 10^{-3} \mathrm{SI}$. Within this zone, fragments of serpentinite and gabbro were recovered during drilling, and the high susceptibilities are probably related to the presence of magnetite in the serpentinites in contrast to the titanomagnetite in the surrounding basalts. The magnetic record indicates that the serpentinite is much more abundant than had been suspected from the recovered core, and is especially abundant between 79 and $89 \mathrm{~m}$ and 99 and $114 \mathrm{~m}$. If that interpretation is correct, then the whole interval is probably composed of some kind of breccia within which fragments of serpentinite and gabbro have been incorporated. Such an interpretation is an important supplement to the information from drilling, and indicates the power of a relatively simple magnetic measurement in filling out the core record.

The second zone of high susceptibility, between 324 and $369 \mathrm{~m}$ sub-basement, where values reach $1.8 \times 4 \pi$ $\times 10^{-3}$ SI units, has a quite different character. It is a smooth, broad bulge in the record and must represent a change in mineralogy of the aphyric pillow lavas in that interval.
Apart from the interval containing serpentinite, the small variation in susceptibility provides a favorable condition for studying the magnetization of the rocks penetrated by the hole as it suggests uniformity of the magnetic carrier.

The variation of the anomalous vertical component of the magnetic field $\left(\mathrm{Z}_{\mathrm{a}}\right)$ down the hole differs markedly from that of the susceptibility. Three units are identified. The upper and lower parts of the section show negative values of $Z_{a}$, and the intervening part of the section shows positive values. Negative values of $Z_{a}$ represent rocks magnetized in the present direction of the Earth's field and thus produced during a period of normal polarity. The positive values of $Z_{a}$ correspond, by contrast, with an interval produced during a period of reversed polarity.

The three units are considered separately.

\section{Unit 1}

This unit runs from the base of the casing at 19 to $170 \mathrm{~m}$ sub-basement (4597-4748 $\mathrm{m}$ below the rig floor). Measurements, of course, could not be made within the steel casing. The upper part of this unit, down to $79 \mathrm{~m}$, is characterized by a uniform anomalous field (about $-1400 \mathrm{nT}$ ) and uniform susceptibility (about $1.3 \times 4 \pi$ $\left.\times 10^{-3} \mathrm{SI}\right)$. The induced field $\left(\mathrm{Z}_{\mathrm{n}}\right)$, calculated as we showed earlier, is about $420 \mathrm{nT}$, and the field ratio $\mathrm{Q}_{z}=$ 2.3. Thus the remanent field is 2 to 3 times the induced field. This part of the unit is petrographic unit $\mathbf{A}_{2}$ of Natland (1979).

Between 79 and $89 \mathrm{~m}$ occurs the first peak in susceptibility referred to earlier, and in this interval the anomalous field remains steady. Below $89 \mathrm{~m}$, starting at the top of the second peak in susceptibility, the anomalous field becomes very irregular, reaching spikes as low as $-6500 \mathrm{nT}$ in some places and positive values in others. The greatest irregularities in the field coincide with the second peak in susceptibility, which probably reflects the presence of serpentinite in the section, but they continue beneath this level to the bottom of the unit at 170 $\mathrm{m}$. Here they appear to have a long wavelength component, with a wavelength of about $7 \mathrm{~m}$ as well as short wavelength spikes.

The fluctuations in the anomalous field in this lower part of Unit 1 may be the result of variations with time of the paleomagnetic field during the solidification and cooling of the basalt. However, they might indicate a certain amount of rotation of parts of the unit after cooling, and could then be related to the brecciation that must have juxtaposed the serpentinite and basalt higher in the section. If this is so, then the whole section between 79 and $170 \mathrm{~m}$ might be disturbed tectonically, through only the upper part was affected enough for serpentinite and gabbros to be emplaced.

\section{Unit 2}

This unit runs from 170 to $475 \mathrm{~m}$ sub-basement and has a positive anomalous field $\left(\mathrm{Z}_{\mathrm{a}}\right)$, corresponding to reversed magnetization. The upper boundary of this unit is not at the depth at which the reversal was placed by Johnson (1979a), but the recovery near this level was 


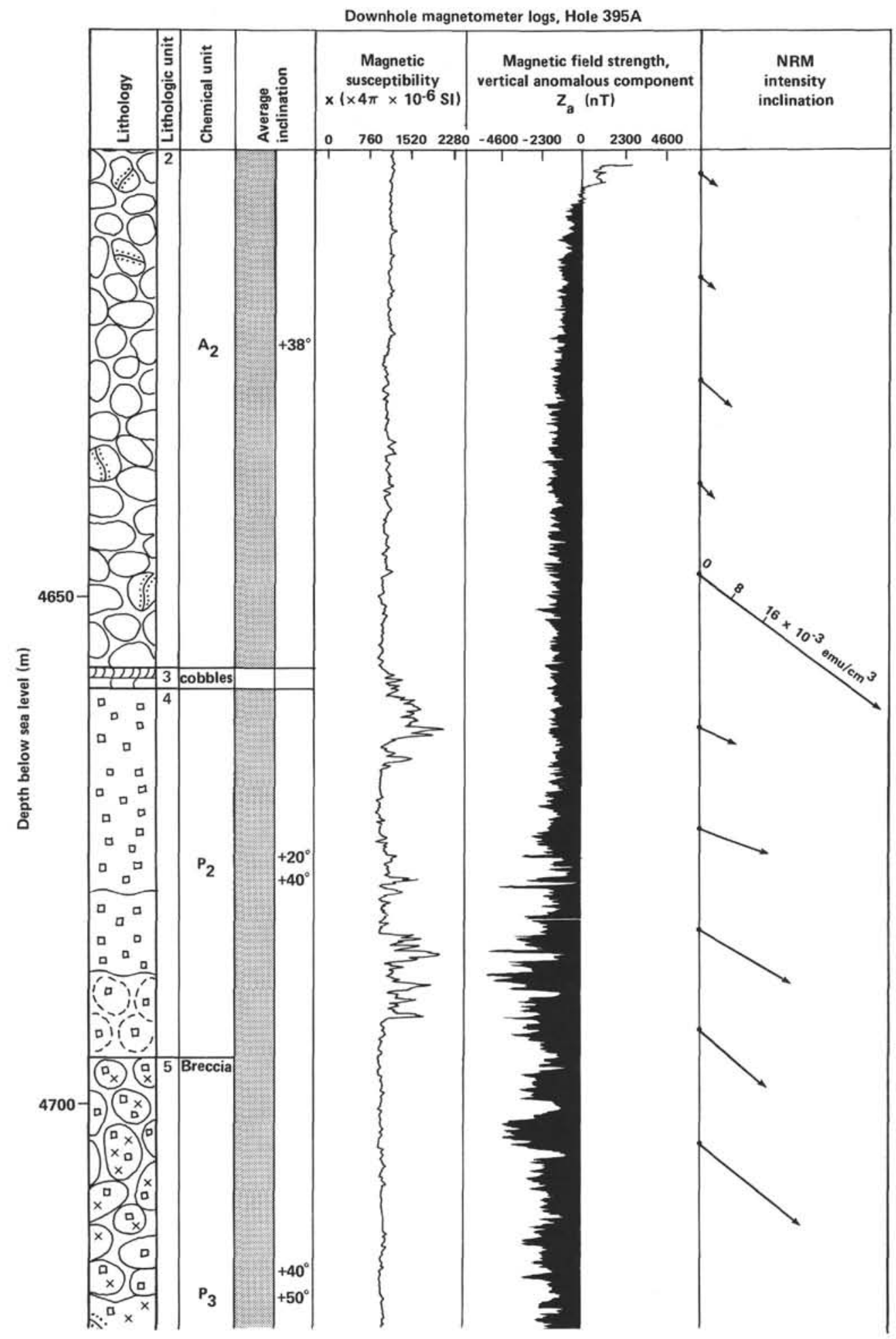

Figure 1. Log of magnetic susceptibility $(\mathrm{x})$ and vertical anomalous component of the magnetic field $\left(\mathrm{Z}_{\mathrm{a}}\right)$ for Hole 395A over the interval 19 to $513 \mathrm{~m}$ sub-basement. (Also added are a lithologic column, simplified from Natland [1979] and paleomagnetic results from minicores taken from Johnson [1979a]. The minicore results are presented as vectors, with dip equal to the measured inclination, and length proportional to the intensity of magnetization after AF demagnetization.) 


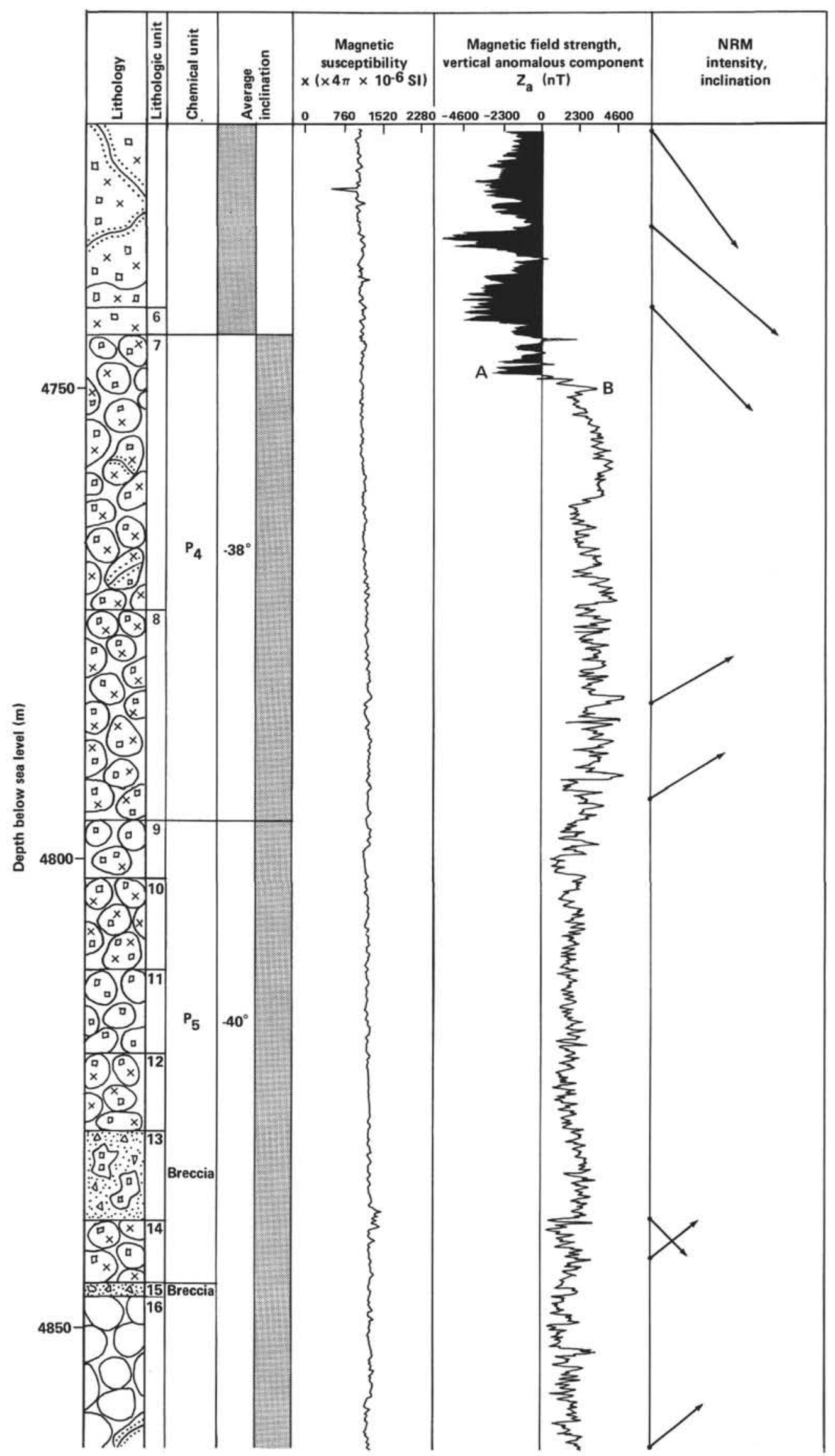

Figure 1. (Continued). 
DOWNHOLE MAGNETIC MEASUREMENTS

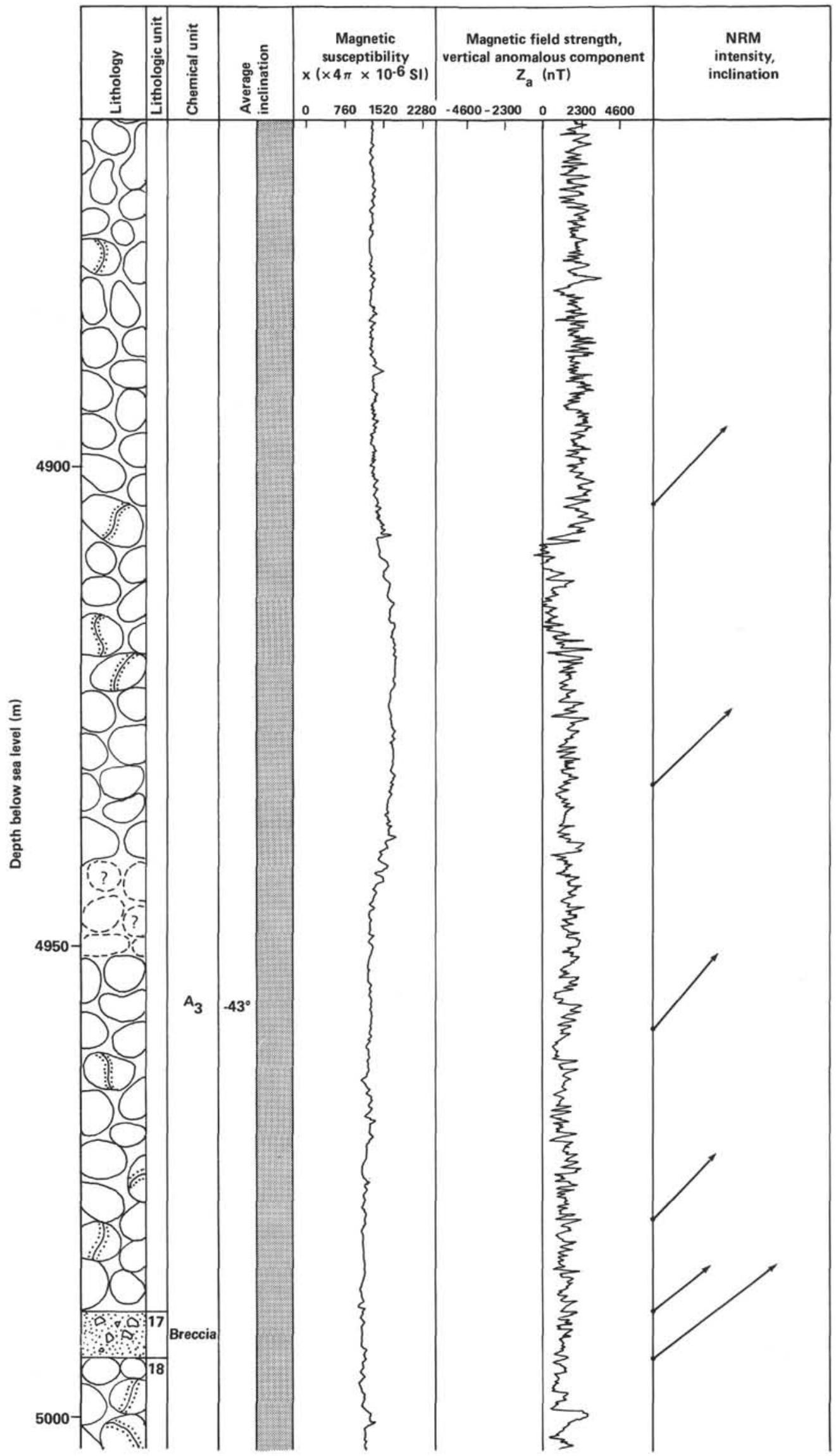

Figure 1. (Continued). 


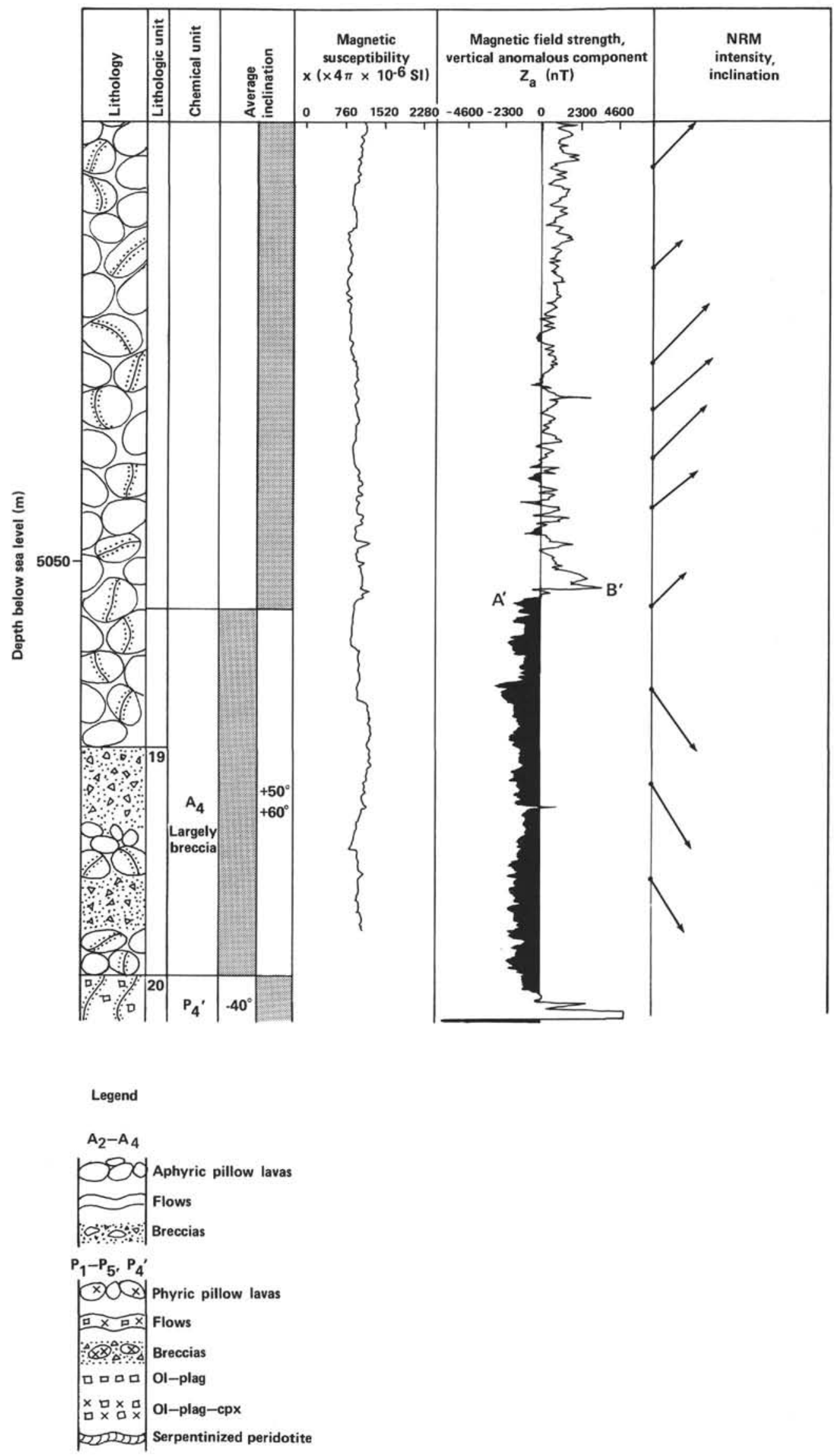

Figure 1. (Continued). 
very poor, and the depth from the magnetic log reported here is likely to be a better estimate.

Throughout the unit, the magnetic susceptibility is relatively constant, apart from the smooth bulge between 324 and $369 \mathrm{~m}$ referred to earlier. The intensity of the vertical component of the anomalous field is high at the top of the unit, reaching $+5000 \mathrm{nT}$, and gradually decreases with depth in the unit to less than $+1000 \mathrm{nT}$ at the base of the unit. At the top the field fluctuates somewhat with depth, but not as strongly as in the lower part of Unit 1, and the amplitude of the fluctuation diminishes below $219 \mathrm{~m}$.

In the upper part of the unit, with $\mathrm{Z}_{\mathrm{a}}=5000 \mathrm{nT}$ and susceptibility $=1.3 \times 4 \pi \times 10^{-3}$ SI units, the ratio $\mathrm{Q}_{\mathrm{z}}$ $=-13$ (where the negative sign represents reversed magnetization).

\section{Unit 3}

This unit extends from the reversal at $475 \mathrm{~m}$ to 513 $\mathrm{m}$, the maximum depth logged by the magnetometer, and, like Unit 1, has normal magnetization. The anomalous field is quite uniform, with an average value of about $-1400 \mathrm{nT}$, and several spikes reaching -1800 to $-2000 \mathrm{nT}$, similar to the upper part of Unit 1 . In the center of Unit 3 for a short interval, $Z_{a}$ is near zero, and for a very short section is positive. At the very bottom of the measured section of the hole at $513 \mathrm{~m}, \mathrm{Z}_{\mathrm{a}}$ becomes positive, perhaps reflecting the top of a section of reversed magnetization as indicated by the sample measurements of Johnson (1979a). However this transition may reflect the steel bit left in the hole about $3 \mathrm{~m}$ below this depth prior to logging.

Comparison of the log of the anomalous vertical component of the field with the results of the paleomagnetic measurements on minicores of Johnson (1979a) can be made from Figure 1. There is a great resemblance between them, but no precise proportionality. The log confirms the magnetic reversals detected from oriented minicores and places them more precisely in the hole, at slightly different levels from those deduced from minicores. The difference in depth may partly be the result of the spot sampling of the minicores, and may perhaps also be caused by differences in depth estimates between Legs 45 and 78B.

The lack of a direct proportionality between $\mathrm{Z}_{\mathrm{a}}$ and the vertical component of the intensity of magnetization of the minicores is not surprising. Not only are the minicores spot samples of the core, but they are biassed toward the zones of continuous core recovery, which represent only part of the recovered material. This in turn is only a $20 \%$ sample of the whole section, and very probably not a random sample either. In addition, the AF demagnetization of the minicores removes all components except the original remanent magnetization, whereas the basalt in the hole retains its full complement of magnetic components. A study of the anomalous field variations within one polarity unit will require a statistical treatment such as outlined by Parker and Daniell (1979).

\section{The Field Reversals}

Now let us make a more detailed analysis of the inversions of the vertical component of the magnetic field at the depths of 170 and $475 \mathrm{~m}$ sub-basement. The two reversal sections are shown on a larger scale in Figure 2. We assume that these represent complete field reversals because of the local field inclination of about $40^{\circ}$, and because the measured inclination in the minicores changes sign but retains the same magnitude at nearly these depths. This assumption is not possible near the equator without measurement of the horizontal components of the field, because small changes in the inclination of the total field vector about its subhorizontal position can cause a change in the sign of the vertical anomalous field, an effect that is well seen in the log from Hole 501 in the Costa Rica Rift (Ponomarev and Nechoroshkov, 1983).

This change in sign of $\mathrm{Z}_{\mathrm{a}}$ at both reversals $(\mathrm{AB}$ and $\mathrm{A}^{\prime} \mathrm{B}^{\prime}$ in Fig. 2) is seen to be over an interval of $1.3 \mathrm{~m}$. However, half the change in each case occurs over a much shorter interval of less than $0.5 \mathrm{~m}$, comparable to the hole diameter. Thus the reversal probably occurs at flow contacts with very little remagnetization. Certainly the reversals are unlikely to have been during continuous lava eruption, as the following argument shows. Submersible observations in the Atlantic and the Pacific have demonstrated that the volcanic section of the oceanic crust commonly accumulates within 500 to $1000 \mathrm{~m}$ of the spreading axis, that is, the limit that lava flows reach from the axial fissures. This corresponds, at 1.5 $\mathrm{cm} / \mathrm{yr}$. half spreading rate, to a time of about $50,000 \mathrm{yr}$. Drilling on Leg 83 (Anderson et al., 1982) showed that the volcanic section there is about $800 \mathrm{~m}$ thick, a similar value to that obtained from ophiolite complexes (e.g., Coleman, 1977); if this section had accumulated continuously, it would represent an eruption rate of $20 \mathrm{~mm} / \mathrm{yr}$. in this area. Because the time required for a reversal to be complete is on the order of 1000 to 10,000 yr. (Doell and Dalrymple, 1966; Ninkovich et al., 1966), the transition would take up at least $20 \mathrm{~m}$ of the section and probably more.

This evidence confirms the view, based on a variety of evidence, that the construction of the volcanic section is episodic. Intervals between construction episodes would thus be long compared with the time taken for a reversal, and the duration of the episodes would be short compared with the time taken for reversal. Relatively few (less than 10) volcanic episodes in the construction of the crust are thus implied, each one lasting perhaps only a few hundred years at most. This is the same view that was reached by Johnson (1979a), though he took the view that the overall period of crustal formation was longer.

\section{CONCLUSIONS}

This second deployment of the downhole magnetometer has illustrated rather different capabilities of the instrument from those seen in the Costa Rica Rift. Because of the large field inclination and the lack of information about the horizontal components of the field, the information from the vertical component of the anomalous field is a useful supplement to that from the minicores, but does not give radically new insights. It does provide a much more representative record of the 


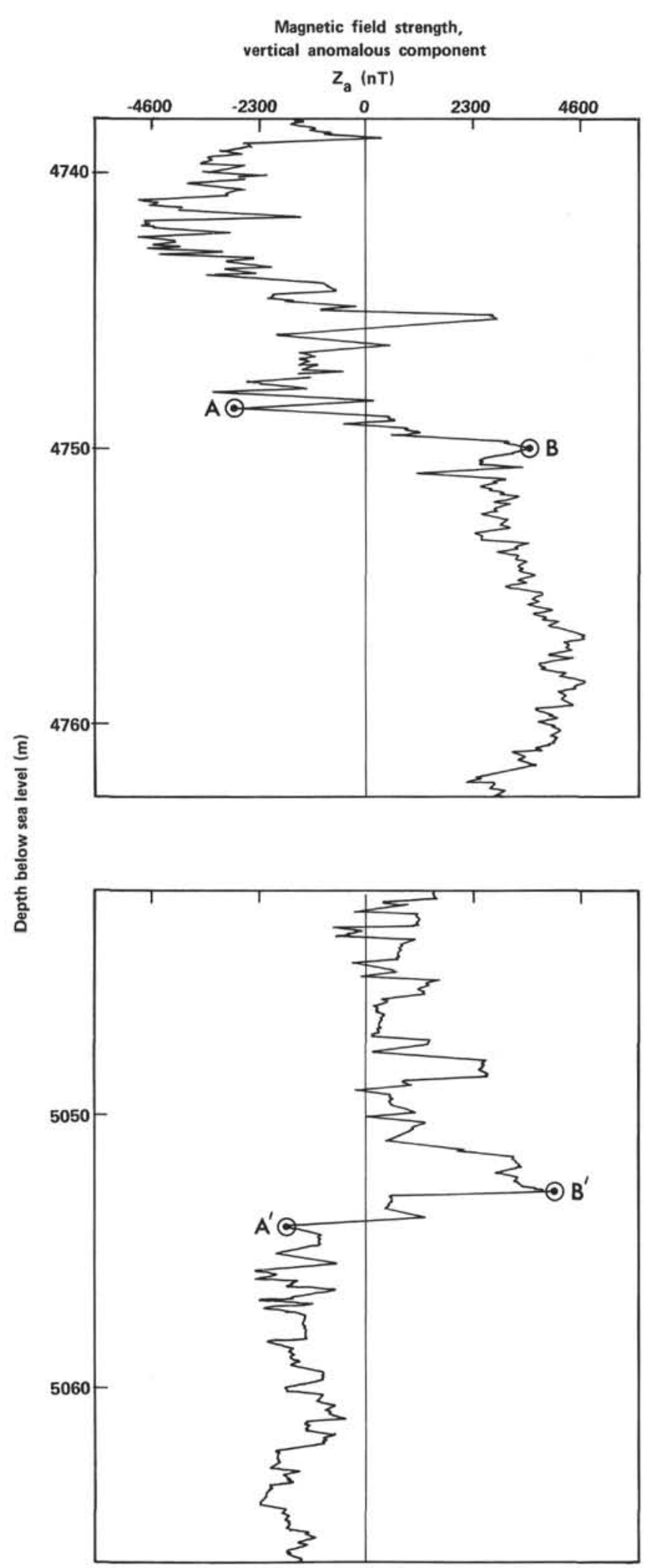

Figure 2. Enlargements of the transitions between magnetic Units 1 and 2 , and 2 and 3 , taken from the $\log$ of the vertical anomalous component of the magnetic field $\left(\mathrm{Z}_{\mathrm{a}}\right)$. (See text for an explantion of points $\mathrm{A}, \mathrm{B}, \mathrm{A}^{\prime}$, and $\mathrm{B}^{\prime}$.) vertical component of magnetization in the rocks, though, and indicates that the minicores may be a biased sample of the whole section. Zones of disturbance in the section may be seen from the variation in $\mathrm{Z}_{\mathrm{a}}$ within individual magnetic units.

However, a more important insight has come from the susceptibility measurements, which show clearly where the highly susceptible serpentinites occur in the hole, and show that the occurrence of serpentinite is much more widespread in the upper part of the hole than had been suspected from the recovered core material. The knowledge of where serpentinite occurs in the hole is of great importance in a geological interpretation of the section, and the susceptibility log is uniquely sensitive in detecting its occurrence. Clearly this tool has considerable potential for the future.

Looking toward the future, one of the most important problems to solve is that of the horizontal components of the field. These can be measured with the present instrument in more inclined holes, but our experience both in the Costa Rica Rift and now in the MidAtlantic Ridge is that Glomar Challenger very often drills holes less than $2^{\circ}$ from the vertical. To obtain the full information from downhole magnetometry, the holes must be drilled more than $2^{\circ}$ from the vertical, some other orientation device must be found, or some means of treating the noisy data from the horizontal components is required to enhance the signal on the present complex traces.

\section{ACKNOWLEDGMENTS}

We acknowledge gratefully the assistance on board ship of the scientific party and the drilling crew, and on land of Roy Hyndman, Joe Cann, and Matt Salisbury, who assisted in the preparation of this manuscript.

\section{REFERENCES}

Anderson, R. N., Honnorez, J., Becker, K., Adamson, A. C., Alt, J. C., Emmermann, R., Kempton, P. D., Kinoshita, H., Laverne, C., Mottl, M. J., and Newmark, R. L., 1982. DSDP Hole 504B, the first reference section over $1 \mathrm{~km}$ through layer 2 of the oceanic crust. Nature, 300:589-594.

Coleman, R. G., 1977. Ophiolites: New York (Springer).

Doell, R. R., and Dalrymple, G. B., 1966. Geomagnetic polarity epochs-a new polarity event and the age of the Brunhes-Matuyama boundary. Science, 152:1060-1061.

Johnson, H. P., 1979a. Paleomagnetism of igneous rock samples, Leg 45. In Melson, W. G., Rabinowitz, P. D., et al., Init. Repts. $D S D P, 45$ : Washington (U.S. Govt. Printing Office), 387-395. 1979b. Rock magnetic properties of igneous rock samples, Leg 45. In Melson, W. G., Rabinowitz, P. D., et al., Init. Repts. DSDP, 45: Washington (U.S. Govt. Printing Office), 397-406.

Melson, W. G., Rabinowitz, P. D., et al., 1979. Init. Repts. DSDP, 45: Washington (U.S. Govt. Printing Office).

Natland, J. H., 1979. Comparison of chemical and magnetic stratigraphy of basement rocks at DSDP Sites 332 and 395. In Melson, W. G., Rabinowitz, P. D., et al., Init. Repts. DSDP, 45: Washington (U.S. Govt. Printing Office), 657-677.

Ninkovich, D., Opdyke, N., Heezen, B. C., and Foster, J. H., 1966. Paleomagnetic stratigraphy, rates of deposition, and tephrachronology in North Pacific deep sea sediments. Earth Planet. Sci. Lett., $1: 476-492$.

Parker, R. L., and Daniell, S. J., 1979. Interpretation of borehole magnetometer data. J. Geophys. Res., 84:5467-5478. 
Ponomarev, V. N., and Bakvalov, A. N., 1969. Borehole magnetic prospecting and magnetic logging. In Zabarovsk, A. I., and Nikitsk, V. E. (Eds.), Handbook of Geophysics Vol. VI: Magnetic Prospecting: Moscow (Nedon), pp. 182-210. (in Russian)

Ponomarev, V. N., and Nechoroshkov, V. L., 1983. First measurements of magnetic field within the ocean crust: DSDP Legs 68 and
69. In Cann, J. R., Langseth, M. G., Honnorez, J., Von Herzen, R. P., White, S. M., et al., Init. Repts. DSDP, 69: Washington (U.S. Govt. Printing Office), 271-279.

Date of Initial Receipt: February 9, 1983

Date of Acceptance: May 11, 1983 